\title{
EFFECT OF ELECTROLYTIC-PLASMA SURFACE STRENGTHENING ON THE STRUCTURE AND PROPERTIES OF STEEL 40KhN
}

\author{
Bauyrzhan RAKHADILOV, Zarina SATBAYEVA, Daryn BAIZHAN \\ Sarsen Amanzholov East Kazakhstan State University, Ust-Kamenogorsk, Republic of Kazakhstan, \\ satbaeva.z@mail.ru
}

https://doi.org/10.37904/metal.2019.739

\begin{abstract}
The paper presents the results of electrolytic-plasma surface hardening (EPSH) of steel $40 \mathrm{KhN}$. The optimal electrolyte composition for EPSH of $40 \mathrm{KhN}$ steel containing $10 \%$ sodium carbonate and $15 \%$ carbamide, which does not cause the surface layer to erosion, oxidation and decarburization, is determined. As a result of EPSH, a modified layer was obtained with increased hardness and wear resistance. We studied the changes in the microhardness of the surface layer of steel $40 \mathrm{KhN}$ after the EPSH, as well as the dependence of the microhardness on the duration of the effect of the electrolyte plasma. The paper presents tests for wear resistance of samples before and after electrolytic-plasma surface hardening. Tests have shown that the treated samples show a significant decrease in wear rate compared with the original sample. To clarify the structural factors affecting the wear resistance of steel, the structural-phase states of the hardened surface layers of steel $40 \mathrm{KhN}$ were investigated. X-ray structural analysis showed that in the initial state the a-phase and cementite $(\mathrm{Fe} 3 \mathrm{C})$ are present in the structure of $40 \mathrm{KhN}$ steel. After the $\mathrm{EPSH}$, diffraction patterns showed a broadening of the interference lines from the crystallographic plane (110). The broadening of the interference line (110) is associated with an increase in the density of dislocations and the formation of martensite and is determined mainly by the tetragonal nature of martensite.
\end{abstract}

Keywords: Electrolytic-plasma surface hardening (EPSH), steel, wear resistance, structure

\section{INTRODUCTION}

Often, the operability of machines and mechanisms depends on the wear resistance of parts of bearing assemblies, gears, camshafts of internal combustion engines and other parts that are often subjected to large shock loads. For durability, the parts must have high strength and hardness of the surface layer in combination with sufficient ductility of the core. Electrolyte-plasma hardening (EPH) is one of the methods of high-speed heating, in which the workpiece is a cathode or anode relative to an aqueous electrolyte. Depending on the heating mode, electrolyte composition, design parameters of the equipment, it is possible to produce hardening, chemical-thermal and thermocyclic processing of materials $[1,3]$. At the same time electrolyticplasma hardening is the most economical and productive method. It is characterized by less energy consumption, simplicity of technological equipment and large size of the hardened zone. The advantages of the method are a sufficiently large process performance and the ability to strengthen the details of a large mass and complex profile [3].

Based on the above, it is relevant to study the effect of electrolytic-plasma hardening regimes on the structural properties of alloyed structural steels.

Table 1 The chemical composition of steel 40HN (GOST 4543-71)

\begin{tabular}{|c|c|c|c|c|c|c|c|}
\hline $\mathrm{C}$ & $\mathrm{Si}$ & $\mathrm{Mn}$ & $\mathrm{Ni}$ & $\mathrm{S}$ & $\mathrm{P}$ & $\mathrm{Cr}$ & $\mathrm{Cu}$ \\
\hline $0.36-0.44$ & $0.17-0.37$ & $0.50-0.80$ & $1.00-1.40$ & $\max .0 .035$ & $\max .0 .035$ & $0.45-0.75$ & max. 0.30 \\
\hline
\end{tabular}


Steel $40 \mathrm{KhN}$ was chosen as the object of study. The choice of research materials is justified by the fact that this steel is widely used in the production of parts for mechanisms operating under constant load conditions. The chemical composition of steel $40 \mathrm{KhN}$ is presented in Table 1.

\section{MATERIAL AND RESEARCH METOD}

Electrolytic-plasma surface hardening of the samples was carried out in a laboratory setup, designed and manufactured at the Surface Engineering and Tribology Research Center at Sarsen Amanzholov East Kazakhstan State University. Test samples for abrasive wear was carried out on an experimental setup according to the scheme "rotating roller - flat surface" in accordance with GOST 23.208-79. The elemental composition of the sample treated in electrolytic plasma was examined on a JSM-6390LV scanning electron microscope (JEOL, Japan), with the addition of an energy dispersive microanalyzer INCA Energy, from OXFORD Instruments. Microhardness measurements were carried out on the device PMT- 3 in accordance with GOST 9450-76. Samples of size $10 \times 10 \times 20 \mathrm{~mm}$ were cut out from the shaft with a diamond disc $1 \mathrm{~mm}$ thick, which was immersed in a coolant. At low cutting speeds $(n=350 \mathrm{rpm})$ and low load $(\mathrm{m}=250 \mathrm{~g})$, the sample does not experience deformation and thermal effects. For metallographic microanalysis, thin sections after polishing using chromium dioxide paste were etched with a $5 \%$ alcoholic solution of nitric acid.

\section{RESULTS AND DISCUSSION}

Aqueous solutions of sodium carbonate [5] are most widely used for the surface hardening of steels. As is known [6,7], for the cathode process, the most optimal component providing a stable discharge is sodium carbonate. In this regard, an electrolyte based on sodium carbonate was chosen for surface hardening. In order to prevent the decarburization process, urea was added to the electrolyte composition. The choice of carbamide is due to the fact that this substance is a source of carbon, as well as characterized by low cost and environmental safety. It is also important to note that urea is highly soluble in water: at $20^{\circ} \mathrm{C}$, the solubility of urea is $51.83 \%$ (mass) [8]. In addition, sodium carbonate interacts well with urea. In this regard, sodium carbonate was chosen as the component providing the optimal electrolyte conductivity, and urea was chosen to prevent the decarburization of the surface.

We selected the following electrolytes containing urea and sodium carbonate with various concentrations for $\mathrm{EPH}$ (Table 2).

Table 2 The composition of the solute

\begin{tabular}{|c|c|c|c|}
\hline \multirow{2}{*}{ Electrolyte number } & \multicolumn{3}{|c|}{ Amount of concentrate and water\% } \\
\cline { 2 - 4 } & Sodium carbonate $\mathrm{Na}_{2} \mathrm{CO}_{3}$ & $\begin{array}{c}\text { Carbamide } \\
\left(\mathrm{NH}_{2}\right)_{2} \mathrm{CO}\end{array}$ & $\begin{array}{c}\text { Water } \\
\mathrm{H}_{2} \mathrm{O}\end{array}$ \\
\hline №1 & 10 & 15 & 75 \\
\hline №2 & 15 & 15 & 70 \\
\hline №3 & 10 & 20 & 70 \\
\hline №4 & 15 & 10 & 75 \\
\hline №5 & 20 & 10 & 70 \\
\hline
\end{tabular}

Figure 1 shows the dependence of the microhardness of steel $40 \mathrm{KhN}$ on the composition of the electrolyte. Electrolyte-plasma hardening was carried out by exposure to electrolytic plasma for 3 seconds, followed by cooling in a flow-through electrolyte. The electrolyte temperature was $\approx 40{ }^{\circ} \mathrm{C}$. It can be seen that the microhardness of the samples increases with an increase in the concentration of urea in the electrolyte and reaches $4420 \mathrm{MPa}$. High hardness is observed in samples treated in electrolytes containing $15 \%$ and $20 \%$ 
carbamide. And the samples treated in electrolytes containing $10 \%$ urea and $15-20 \%$ sodium carbonate showed the lowest hardness. This is probably due to the decarburization of the surface layer. Thus, carbamide contains carbon in greater quantities than sodium carbonate, which means that the high content of carbamide prevents the decarburization of the surface. At the same time, a change in the concentration of sodium carbonate does not lead to a significant change in the surface hardness.

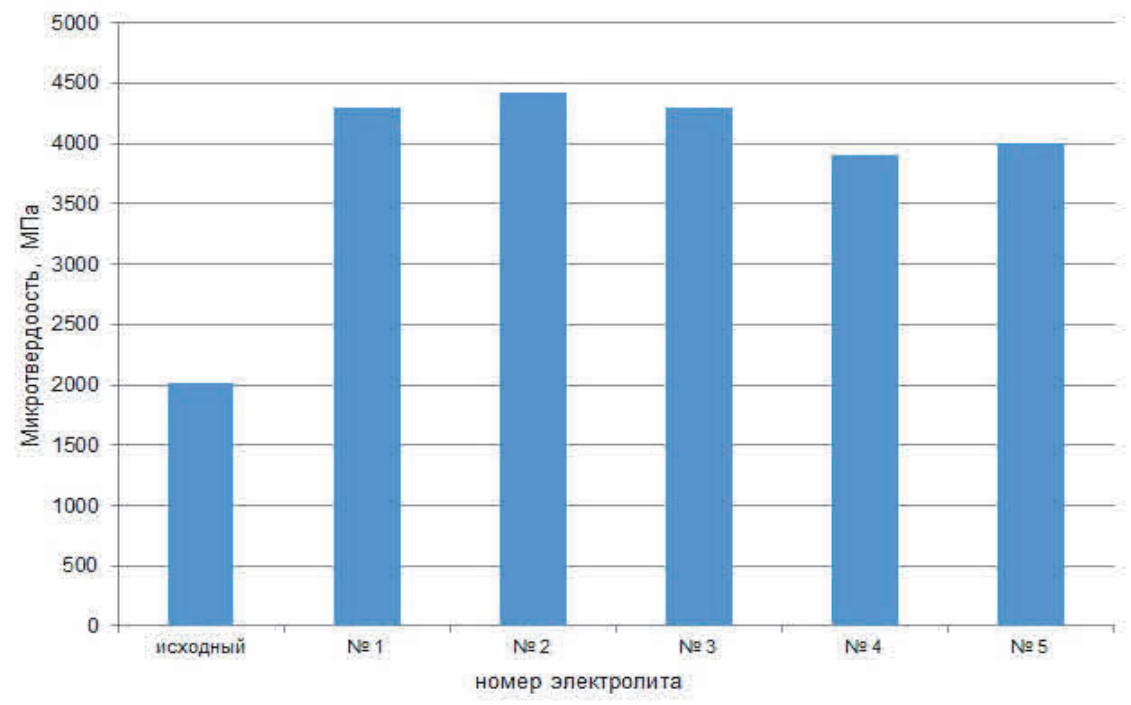

Figure 1 The dependence of the microhardness of steel $40 \mathrm{XH}$ from the electrolyte composition

Thus, we have obtained the most optimal electrolyte composition for electrolyte-plasma surface quenching of steels, which does not cause the surface layer to erosion, oxidation and decarburization. Such an electrolyte is an electrolyte containing up to $15 \%$ sodium carbonate and $15 \%$ carbamide. In addition, using this electrolyte produces a stable, stable discharge.

Table 2 shows the wear rate of steel samples $40 \mathrm{KhN}$ before and after EPH. Tests conducted by the scheme "ball - disk". It can be seen that the treated sample shows a significant decrease in wear rate in comparison with the original sample, which indicates a significant increase in wear resistance of steels. The results of testing samples for abrasive wear were characterized by the amount of wear of the samples after the test. Table 2 shows the amount of wear of the sample steel $40 \mathrm{KhN}$ before and after hardening of the EPH. It is seen that the amount of wear of the hardened sample is less than that of the non-hardened sample, which indicates an increase in the resistance to abrasive wear of $40 \mathrm{KhN}$ after surface hardening. Changes in the microhardness of the surface layer of $40 \mathrm{KhN}$ steel after EPH were studied.

Table 3 shows the dependences of the microhardness of steel $40 \mathrm{KhN}$ on the duration of exposure to electrolytic plasma. It is seen that the microhardness of steel $40 \mathrm{KhN}$ after EPH increases by 2 times, depending on the initial state.

Table 3 The results of the study of microhardness and wear resistance of steel $40 \mathrm{KhN}$ before and after EPH

\begin{tabular}{|c|c|c|c|}
\hline Sample Name & $\begin{array}{c}\text { Microhardness, } \\
\mathrm{MPa}\end{array}$ & $\begin{array}{c}\text { Wear rate, } \\
\left(\mathrm{MM}^{3} / \mathrm{H} \times \mathrm{M}\right)\end{array}$ & $\begin{array}{c}\text { The amount of wear, } \\
\mathrm{mm}^{3}\end{array}$ \\
\hline 40XH initial & 2030 & 8.9 & 11.03 \\
\hline 40XH after EPS, 3 c & 4407 & 0.28 & 0.07 \\
\hline
\end{tabular}

The microstructure of the cross-section of $40 \mathrm{KhN}$ steel after electrolytic-plasma surface hardening is shown in Figure 2. From Figure 2 it can be seen that the structure of the cross-section of steel is conventionally divided into 3 zones: there is zone 1 on the surface - hardened layer; zone 2 - heat-affected layer; zone 3 - matrix. The 
hardened layer is a homogeneous fine-grained martensitic structure. As the depth increases, a non-uniform structure is formed - a heat-affected zone, which is martensite and perlite. Then this zone turns into a pearliteferritic structure, i.e. in the structure of the matrix. The thickness of the modified layer is $1-1.2 \mathrm{~mm}$.

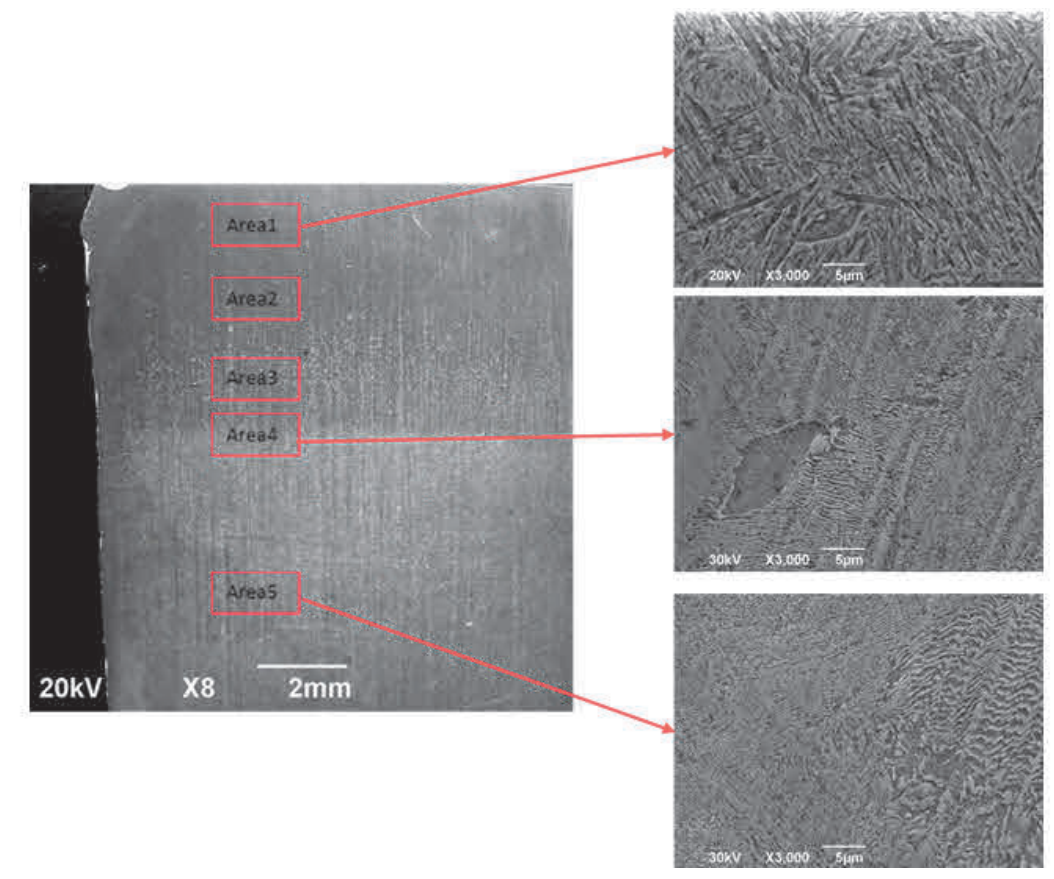

Figure 2 The microstructure of the cross-section of steel $40 \mathrm{KhN}$ after EPH with a heating time of $3 \mathrm{~s}$

In the aim of detecting changes in the elemental composition of the surface, an energy-dispersive analysis of the surface of steel samples $40 \mathrm{KhN}$ was carried out before and after EPH. Figure 3 shows the results of energy dispersive analysis. After EPH, no significant changes in the elemental composition of the steel $40 \mathrm{KhN}$ surface are observed.
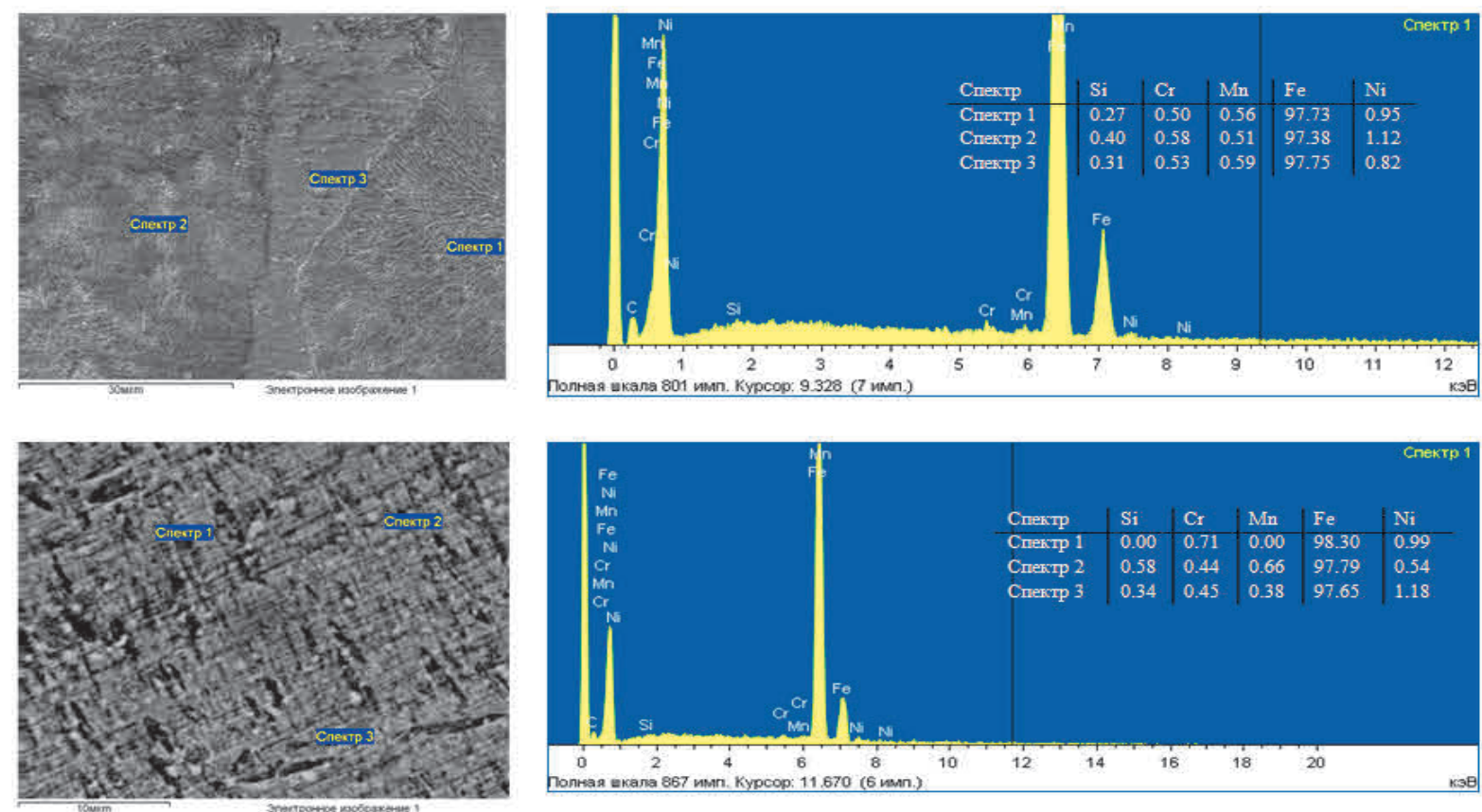

a) - before, b) - after EPS with a heating period of 3 seconds

Figure 3 Results of X-ray microanalysis of the steel surface 40XN 
Figure 4 shows the X-ray diffractogram of steel $40 \mathrm{KhN}$ before and after EPH. X-ray structural analysis showed that in the initial state, that is, after standard heat treatment, the $\alpha$-phase and cementite (Fe3C) are present in the structure of $40 \mathrm{KhN}$ steel. After $\mathrm{EPH}$, diffraction patterns show a broadening of interference lines from the (110) crystallographic plane. The broadening of the interference line (110) is associated with an increase in the density of dislocations and the formation of martensite and is determined mainly by the tetragonal nature of martensite [8].
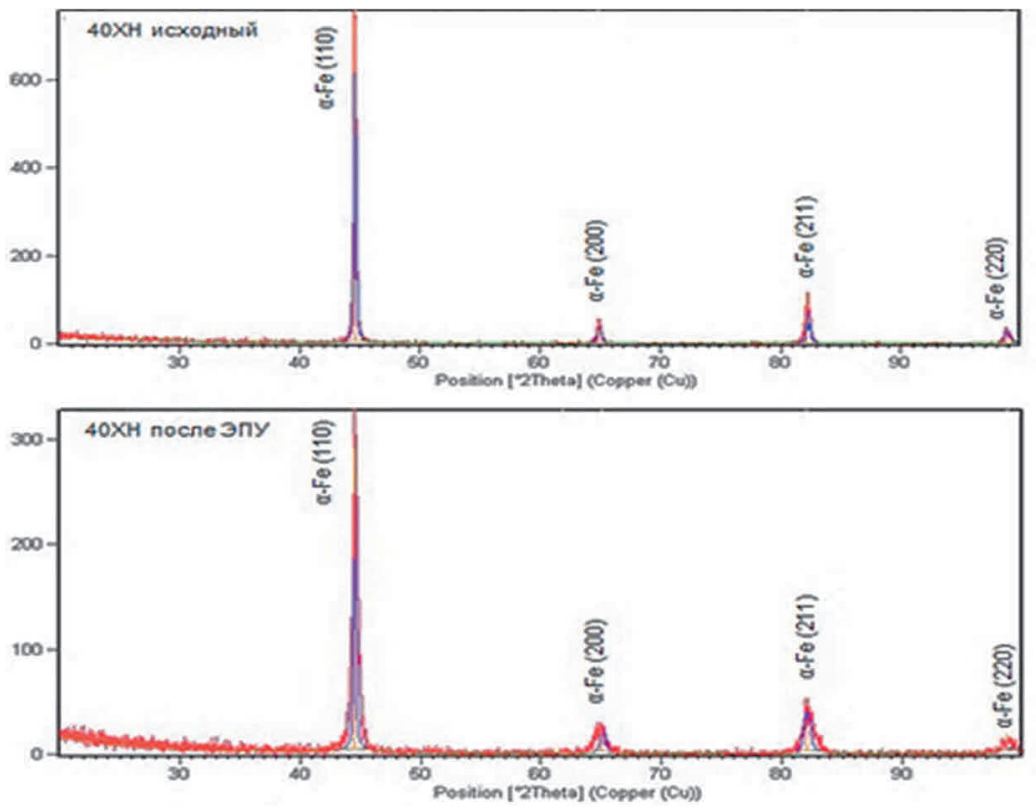

Figure 4 Diffractogram of steel $40 \mathrm{KhN}$ before and after EPH

Thus, the main advantage of EPH is the possibility of obtaining a modified layer on the surface of steels consisting of martensite with carbide particles. In this case, the basis of the material does not change, it consists of a ferritic-pearlitic structure, i.e. the part retains its viscous core.

\section{CONCLUSION}

Analyzing the experimental results obtained in the work, we can draw the following conclusions:

1) It was determined that the most optimal electrolyte composition for electrolyte-plasma surface hardening of steels that does not cause the surface layer to erosion, oxidation and decarburization are electrolytes containing up to $15 \%$ sodium carbonate and $15 \%$ carbamide. It is established that an increase in the concentration of sodium carbonate in the electrolyte leads to an increase in the surface roughness parameter.

2) It was established that after EPH a modified layer with a thickness of 1-1.2 mm with high hardness and wear resistance is formed, consisting of a hardened layer of fine-grained martensite, an intermediate layer of pearlite and martensite.

3) It has been established that after EPH, the microhardness and wear resistance of steel 40Kh increases, depending on the processing mode. After an EPH with a heating time of $3 \mathrm{~s}$, the microhardness increases up to 2 times, the wear resistance increases up to 30 times. High wear resistance of steels after EPH is associated with the formation of fragmented martensite with dispersed carbides.

\section{ACKNOWLEDGEMENTS}

This work was supported by grant of the Committee of Science, Ministry of Education and Science of the Republic of Kazakhstan (BR05236748, 2018-202). 


\section{REFERENCES}

[1] SAMOTUGIN, S.S. Plasma micro and nanostructuring of the surface of tool steels / S.S. Samotugin, V.A. Mazur // Strengthening technologies and coatings. 2013. № 4. pp 29-37.

[2] Handbook of Hard Coatings. Deposition Technolgies, Properties and Applications. Edited by Rointan F. Bunshah. University of California, Los Angeles, USA. 2001. P 538.

[3] The method of surface hardening of steel products: Patent for the invention of the Republic of Kazakhstan; IPC C21D 1/09 /; RAKHADILOV B.K., SKAKOV M.K., SAGDOLDINA ZH.B., KENESBEKOV A.B. Publ. 06/04/2018 Byul. No. 20

[4] BROWN E.D., BUSH N.A., BUYANOVSKY I.A. et al. Fundamentals of tribology (friction, wear, lubrication) / ed. A.V. Chichinadze: Textbook for Technical Universities, 2nd edition. M.: Center "Science and Technology", 2001. p 778.

[5] BELKIN P.N. Anodic electrochemical-thermal modification of metals and alloys // Electronic processing of materials. 2010. T.46 (6). pp 29-41.

[6] DURAJI V.N., PARSADANYAN A.S. Heating metals in electrolyte plasma. Chisinau: Shtiintsa, 1988. p. 216.

[7] TYURIN Y.N., POGREBNYAK A.D., Electric Heating Using Liquid Electrode, Surface and Coatings Technology, 142-144, 2001. pp 293-299.

[8] A. A. SOKOLOVSKY, E. V. YASHKE. Technology of mineral fertilizers and acids: a textbook for chemical engineering schools: add. M-higher. and n specialist. Education USSR. 2nd ed., Rechanges. and add. Moscow: Chemistry, 1979. p 384.

[9] BERNSTEIN M.L., ZAYMOVSKY V.A., KAPUTKINA L.M. Thermomechanical processing of steel. M.: Metallurgy, 1983. p 480 . 